\title{
INFLUÊNCIA DA UTILIZAÇÃO DE ANTRACITO SOBRE A RESISTÊNCIA À COMPRESSÃO DAS PELOTAS DE MINÉRIO DE FERRO *
}

\author{
Manoel Farias Martins ${ }^{1}$ \\ Márcio Rezende ${ }^{2}$ \\ Ramiro Conceição Nascimento ${ }^{3}$
}

\begin{abstract}
Resumo
A utilização de antracito na produção de pelotas de minério de ferro é uma prática utilizada pelas mineradoras para reduzir custos com combustíveis e melhorar a qualidade física do produto. Objetivando uma melhor compreensão dos efeitos ocasionados pela adição de carvão na mistura (pellet feed moído e aditivos) sobre a resistência a compressão das pelotas queimadas, foram confrontados os resultados dos ensaios de resistência à compressão obtidos através da rotina de ensaios da mineradora VALE SA, com as seguintes variáveis: percentual em massa de carbono (\%C fixo), porosidade e granulometria do antracito. Com a elevação de carbono, observou-se a redução nos valores da resistência à compressão, sobretudo, nas pelotas de redução direta. No que diz respeito à porosidade, a resistência à compressão das pelotas aumentou com a diminuição dos poros no interior das mesmas. Analisou-se também a granulometria do carvão, todavia, constatou-se que a mesma não teve influência significativa sobre os resultados da resistência à compressão.
\end{abstract}

Palavras-chave: Pelotas de Minério de Ferro; Carbono Fixo; Resistência à Compressão.

\section{INFLUENCE OF THE USE OF ANTHRACITE COAL ON IRON ORE PELLETS COMPRESSION STRENGTH}

\section{Abstract}

The use of anthracite in the production of iron ore pellets is a practice used by miners to reduce fuel costs and improve the physical quality of the product. Aiming at a better understanding of the effects caused by the addition of coal in the mixture (pellet feed and additives) on the compressive strength of the pellets burned, the results of the compression tests obtained through the VALE SA mining routine were compared, with the following variables: percentage of carbon mass (\% C fixed), porosity and granulometry of anthracite. With the elevation of carbon, there was a reduction in the compression values, especially in the direct reduction pellets. As far as porosity is concerned, the resistance of the pellets increased with the decrease of the pores inside the pellets. It was also analyzed the coal granulometry, however, it was verified that this little influenced the results of resistance to compression.

Keywords: Iron Ore Pellets; Fixed Carbon; Compression Strength.

1 Engenharia de Materiais, Mestrando, Técnico de Controle de Processo, DIPE- Diretoria de Pelotização - Vale SA / Instituto Federal do Espírito Santo - IFES, Vitória, Espirito Santo, Brasil.

2 Engenharia de Produção, Bacharel, Técnico Especializado de Processo, DIPE- Diretoria de Pelotização - Vale SA, Vitória, Espírito Santo, Brasil.

3 Engenharia Metalúrgica, Doutorado, Professor / Pesquisador, Departamento de Metalurgia, IFES Instituto Federal do Espírito Santo, Vitória, Espirito Santo, Brasil. 


\section{INTRODUÇÃO}

As siderúrgicas utilizam minério de ferro sob 3 formas: minério granulado, sinter e pelotas. As pelotas são produzidas através de um processo de aglomeração denominado de pelotização. Este processo consiste em aglomerar finos de minérios, com granulometria inferior a $0,15 \mathrm{~mm}$ e moído para atingir $90 \%$ abaixo da fração granulométrica de $0,045 \mathrm{~mm}$, conhecido como pellet feed moido, em pelotas com diâmetros variando entre 8 a 18 mm [1].

Devido às distâncias existentes entre as mineradoras que produzem pelotas de minério de ferro e as siderúrgicas, o produto necessita de resistência mecânica suficiente para suportar o transporte e manuseio até o destino final. Além disso, a qualidade física das pelotas é essencial para o bom rendimento dos módulos de redução. As propriedades químicas, físicas e metalúrgicas das pelotas são influenciadas pela tipologia e natureza do minério (concentrado), pelos aditivos e tratamento térmico utilizado no processo de produção destas [2].

Há uma relação direta da granulometria e superfície específica do fino de minério com a resistência à compressão das pelotas cruas e queimadas, de modo que, a resistência é favorecida com a diminuição do tamanho e/ou aumento da superfície especifica dos grãos. O aumento do percentual de poros, causado por diversos motivos, nas pelotas é um fator que contribui para o decréscimo da compressão [23].

Dentre alguns aditivos que são adicionados no processo de pelotização, o antracito é utilizado no processo com a finalidade de reduzir o consumo do combustível (óleo e/ou gás natural) e promover uma queima mais eficiente melhorando a qualidade física das pelotas, com um melhor aproveitamento do combustível e do ar de combustão. Porém, a granulometria e o percentual em massa de carvão adicionado fora do especificado diminui a resistência à compressão das pelotas queimadas [4, $5,6]$. Existe uma relação entre a porcentagem em massa de carbono $(\% \mathrm{C}$ fixo) e os resultados de compressão das pelotas queimadas [3]. A Figura 1 apresenta de forma gráfica a relação entre a quantidade de carvão adicionado versus resistência à compressão para minérios hematíticos e magnetíticos.

Em relação ao ciclo térmico, há uma temperatura que maximiza a resistência à compressão das pelotas, explicado pelo fato de que em temperaturas baixas não há formação de fases líquidas suficientes para elevar a resistência das pelotas, já para temperaturas elevadas a redução à magnetita é favorecida resultando na queda da resistência física do produto [7-8].

O presente trabalho tem como objetivo analisar a influência da utilização do carvão (antracito) no processo de pelotização sobre a resistência à compressão das pelotas queimadas. O estudo focou em variáveis como percentual em massa de carbono (\%C fixo), porosidade e granulometria do antracito utilizado no processo de pelotização. Por fim, foi realizada uma correlação de tais variáveis com os resultados de resistência à compressão das pelotas em questão. 


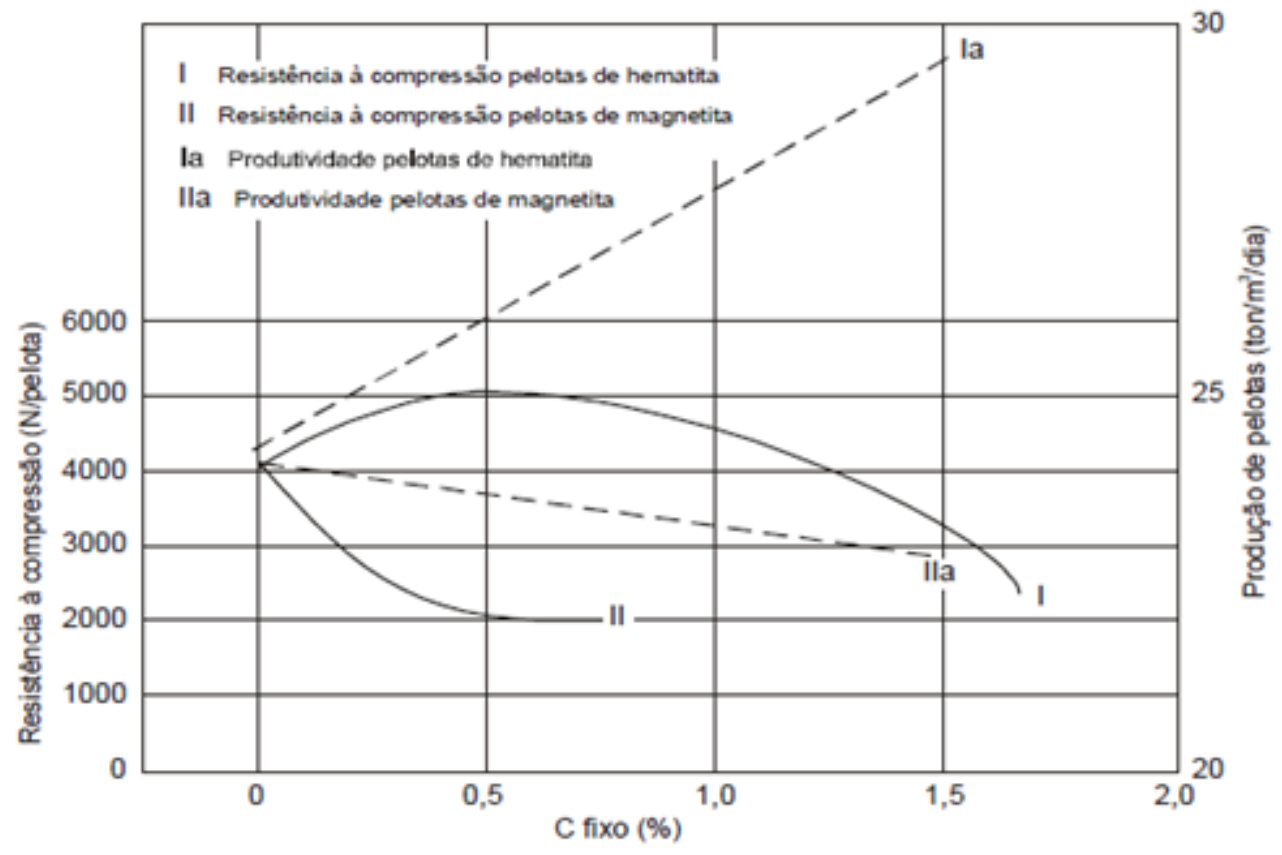

Figura 1 - Relação do \%C fixo sobre compressão para pelotas de hematita (I) e magnetita (II) [3]

\section{MATERIAIS E MÉTODOS}

As amostras de pelotas de minério de ferro, utilizadas no estudo, foram obtidas da mineradora Vale SA. As Tabelas 1 e 2 apresentam as composições químicas específicas para dois tipos de pelotas comercializadas pela empresa. Foram considerados os tipos alto-forno (AF) e redução direta $(\mathrm{RD})$ destinado ao reator tipo Midrex.

Tabela 1 - Composição química típica de pelotas de alto-forno

\begin{tabular}{llllllllll}
\hline $\mathrm{Fe}$ & $\mathrm{SiO}_{2}$ & $\mathrm{Al}_{2} \mathrm{O}_{3}$ & $\mathrm{CaO}$ & $\mathrm{MgO}$ & $\mathbf{P}$ & $\mathrm{Mn}$ & $\mathrm{TiO}_{2}$ & $\mathbf{S}$ & Bas.2 \\
\hline 66,26 & 2,11 & 0,48 & 2,33 & 0,07 & 0,02 & 0,05 & 0,06 & 0,005 & 1,10 \\
\hline
\end{tabular}

Fonte: Autor, 2016.

Tabela 2 - Composição química típica de pelotas de redução direta - Reator Midrex

\begin{tabular}{llllllllll}
\hline $\mathbf{F e}$ & $\mathrm{SiO}_{2}$ & $\mathrm{Al}_{2} \mathrm{O}_{3}$ & $\mathrm{CaO}$ & $\mathrm{MgO}$ & $\mathbf{P}$ & $\mathbf{M n}$ & $\mathrm{TiO}_{2}$ & $\mathbf{S}$ & Bas.2 \\
\hline 67,97 & 1,37 & 0,41 & 0,74 & 0,04 & 0,02 & 0,05 & 0,07 & 0,003 & 0,54 \\
\hline
\end{tabular}

Fonte: Autor, 2016.

A Tabela 3 mostra a composição típica do antracito adicionado no pellet feed moído para a produção das pelotas. Além das amostras, todos os ensaios físicos e químicos foram realizados com os recursos e equipamentos da empresa supracitada. 
Tabela 3 - Composição típica do antracito utilizado

\begin{tabular}{lllllll}
\hline Cinzas (\%) & Voláteis (\%) & C. fixo (\%) & S (\%) & Umidade (\%) & PCl (kcal/Kg) & PCS (kcal/Kg) \\
\hline 16,08 & 10,64 & 73,43 & 1,2 & 6,37 & 6742 & 6926 \\
\hline
\end{tabular}

Fonte: Autor, 2016.

\subsection{Ensaio de Resistência à Compressão}

Para cada teste de resistência à compressão, as pelotas foram previamente selecionadas a fim de atender aos requisitos do padrão descrito na norma ISO 4700 , ano 2007. Já com as pelotas aptas ao ensaio, as mesmas foram comprimidas individualmente utilizando uma prensa hidráulica do fabricante AUTOMÁTICA Tecnologia. O equipamento possui célula de carga com capacidade de 20 kN (2040 kgf) acoplada a um computador munido de um software especifico para o teste. Ao final de cada ensaio, foi obtido o valor médio da carga suportada por 100 pelotas (resistência à compressão propriamente dita), o desvio padrão, o máximo e o mínimo da carga suportada por uma pelota. Para fins práticos, foi utilizado apenas o valor médio de compressão de cada ensaio dado em decanewton por pelota (daN/p).

\subsection{Determinação do Percentual em Massa de Carbono (\%C fixo) e Granulometria do Antracito Utilizado na Mistura.}

O ensaio para determinar o percentual em massa de carbono na mistura, foi realizado com uma amostra de pellet feed moido já adicionado carvão, denominada de polpa retida, a mesma é retirada na etapa de filtragem, preparada e conduzida para o aparelho LECO CS600 que realiza a análise quantitativa de todo carbono contido na composição. O percentual em massa de carbono (\%C fixo) do antracito contido na polpa retida é obtido por estequiometria levando-se em consideração os demais aditivos presentes que também possui carbono em sua estrutura.

Para a análise de granulometria do carvão, foi utilizado um peneirador do tipo Alpine modelo AS 200 jet do fabricante Retsch, para esse ensaio foi colocado $5 \mathrm{~g}$ de antracito finamente moído sobre a peneira com malha de $0,045 \mathrm{~mm}$, após 1 minuto de sucção foi retirado e pesado todo o material retido na referida malha utilizada. 0 resultado é obtido conforme a Equação 1.

$$
\% G r<0,045 m m=\left(P_{1}-P_{2}\right) / P_{1} * 100
$$

Onde:

$\% \mathrm{Gr}<0,045 \mathrm{~mm}$ é o percentual da amostra passante na malha de 0,045 mm;

$\mathrm{P}_{1}$ é a massa inicial da amostra, no caso $5 \mathrm{~g}$;

$P_{2}$ é a massa retida na malha de $0,045 \mathrm{~mm}$; 


\subsection{Ensaio de Porosidade}

O ensaio de porosidade foi realizado com base na norma ISO 4698, ano 2008, para este, são utilizadas 18 pelotas previamente selecionadas de acordo com os critérios estabelecidos para o teste em questão. Foi utilizado um porosímetro automático da empresa AUTOMÁTICA Tecnologia, o qual extraiu características físicas, tais como: peso(g), diâmetro $(\mathrm{mm})$, volume $\left(\mathrm{cm}^{3}\right)$, densidade aparente $\left(\mathrm{g} / \mathrm{cm}^{3}\right)$ e porosidade (\%). Uma vez obtida à densidade aparente de cada pelota, o aparelho compara com - valor correspondente à densidade real de uma pelota maciça de mesma dimensão, logo, a porosidade obtida representa a diferente entre a densidade real e aparente das pelotas utilizadas dado em porcentagem (\%).

\section{RESULTADOS E DISCUSSÃO}

\subsection{Influência do Percentual em Massa do Carbono Fixo Sobre a Resistência a Compressão}

A Figura 2 apresenta a variação em massa do percentual de carbono fixo (\%C fixo) e a relação com a resistência à compressão das pelotas produzidas nas usinas da mineradora. Inicialmente, foram analisadas pelotas do tipo redução direta. $O$ banco de dados foi composto por 106 resultados cujos valores médios em massa do carbono fixo e compressão foram respectivamente 1,16\% e 307 daN/p. É notável que à medida que $0 \% \mathrm{C}$ fixo decresce, o resultado da resistência à compressão aumenta, tal fato, está em conformidade com a literatura analisada [3]

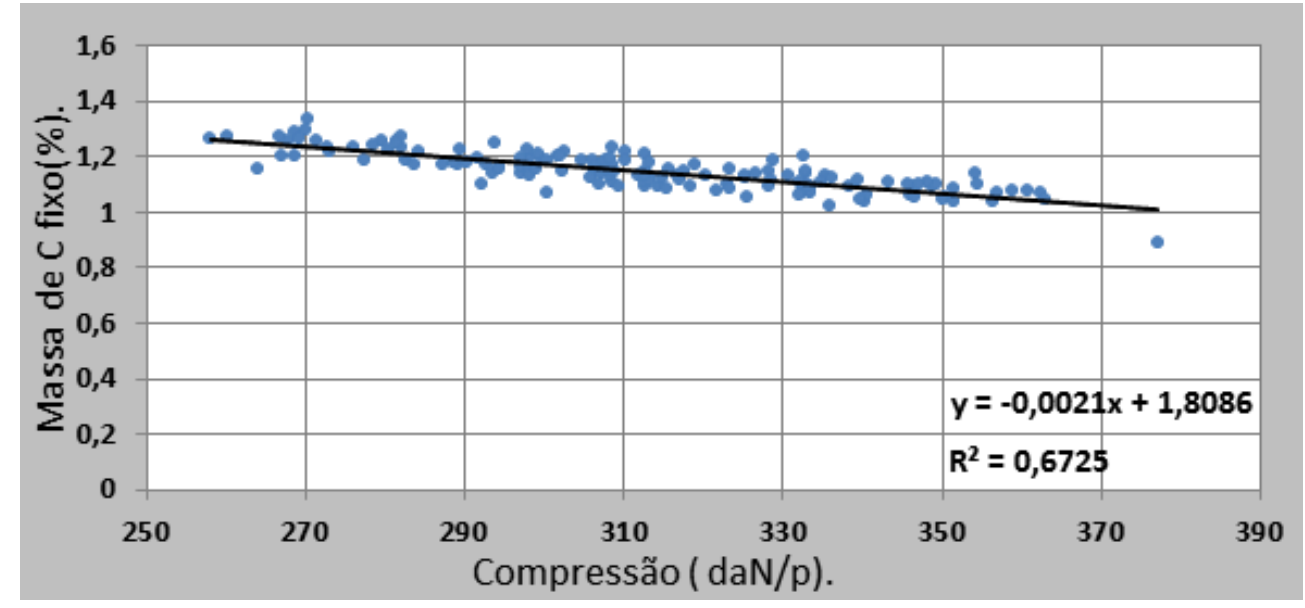

Figura 2 - Relação do \%C fixo sobre a compressão - Pelotas RD.

A Figura 3 apresenta os resultados das pelotas destinadas para alto-forno, para esta análise, utilizamos uma amostragem com 89 resultados cujos valores médio das variáveis foram $1,27 \%$ de carbono fixo e 294 daN/P para compressão. A interpretação dos resultados, é exatamente a mesma da Figura 2, ou seja, a compressão eleva à medida que o \%C fixo é reduzido. 


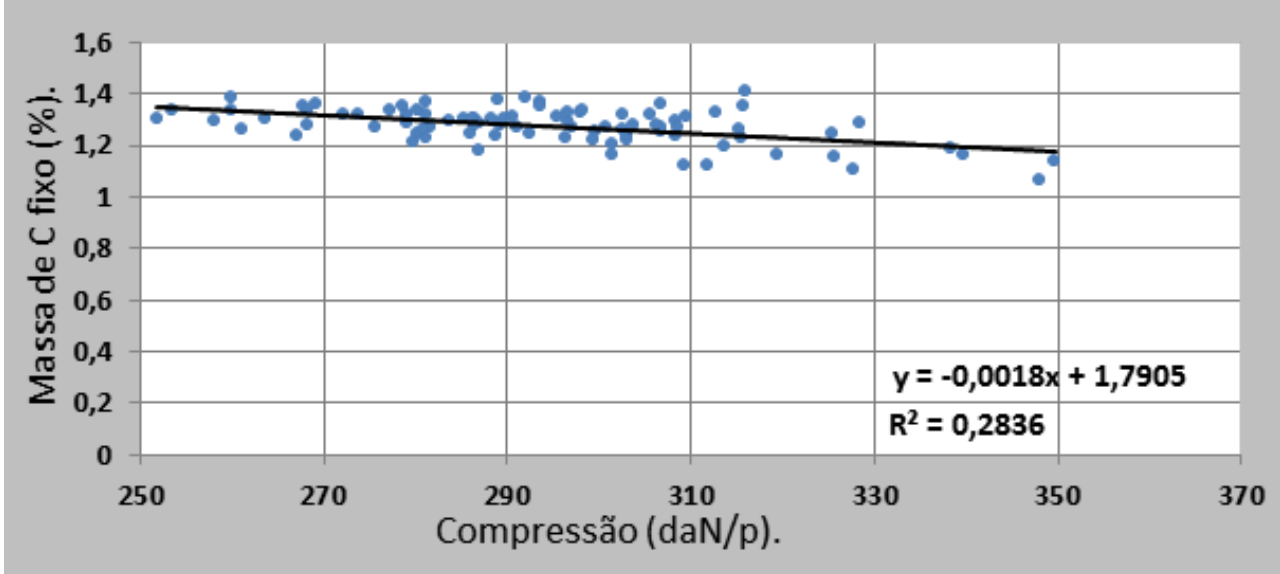

Figura 3 - Relação do \%C fixo sobre a compressão - Pelotas AF.

\subsection{Efeito do percentual em Massa de carbono fixo sobre a porosidade das pelotas}

Para entendermos melhor a relação do \%C fixo adicionado sobre a porosidade das pelotas, analisamos os resultados dessa variável para as pelotas RD e AF. As Figuras 4 e 5 apresentam a influência do \%C fixo sobre a porosidade para os tipos de pelotas em questão.

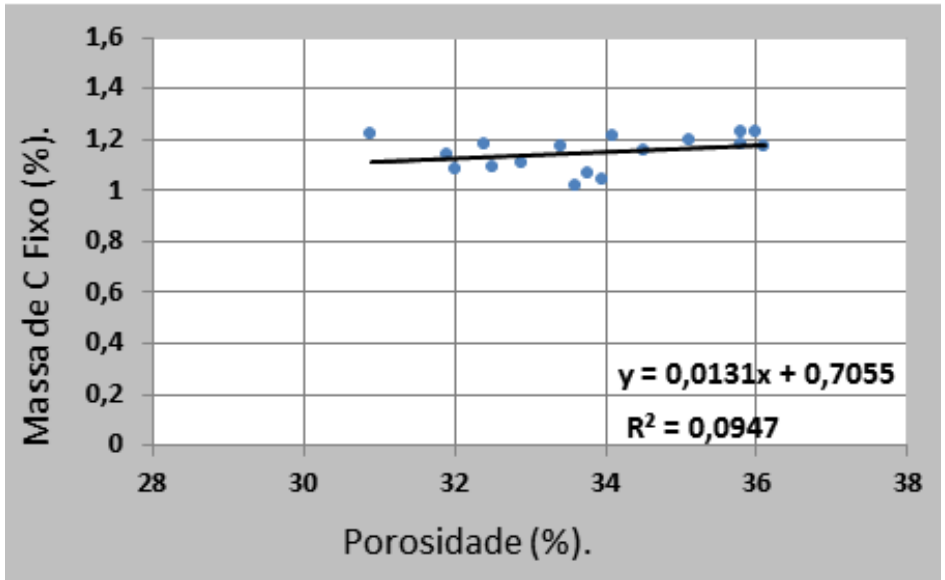

Figura 4 - Influência do \%C fixo sobre a porosidade - Pelotas RD.

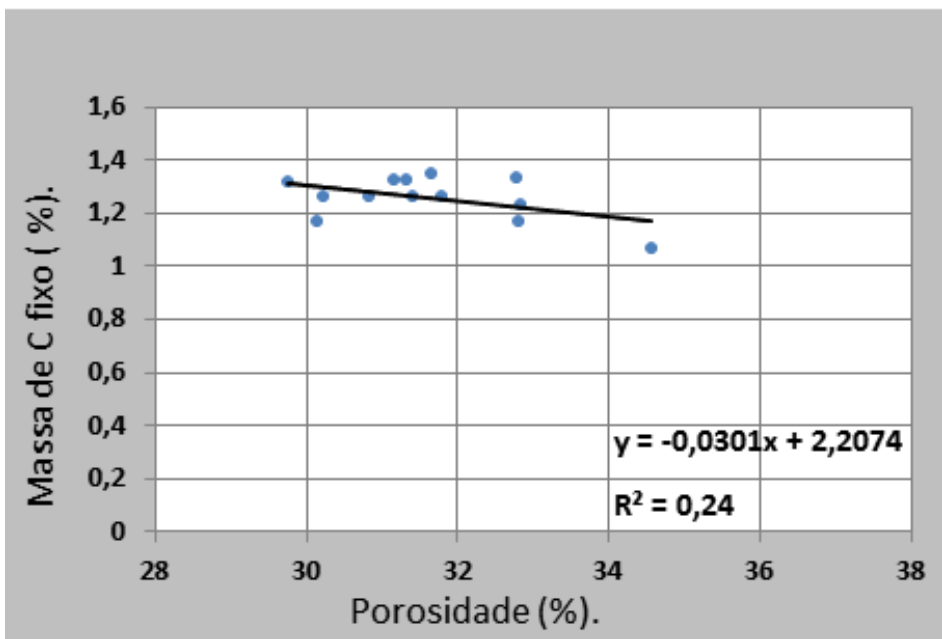

Figura 5 - Influência do \%C fixo sobre a porosidade - Pelotas AF. 
O efeito do percentual de carbono fixo sobre a porosidade apresentou comportamento distinto para os dois tipos de pelotas analisadas. $\mathrm{O}$ alto teor de $\% \mathrm{C}$ fixo quando adicionado nas pelotas AF, durante o tratamento térmico, eleva a temperatura no interior das pelotas que aliada a uma maior quantidade de calcário (fundente), forma pontos eutéticos com o minério de ferro e consequentemente abaixa a temperatura de formação da fase líquida dos elementos químicos presentes na pelota. Sendo assim, haverá uma quantidade satisfatória de material líquido que preencherá boa parte dos poros formados pela combustão do antracito e de outros mecanismos do processo, conforme exposto por [8]. Já para as pelotas de redução direta, o alto \%C fixo mesmo elevando a temperatura no interior das pelotas, o calcário utilizado é insuficiente para formar uma quantidade de fase líquida capaz de preencher os poros deixados pela combustão do carvão e os outros já existentes.

\subsection{Efeito da granulometria do carvão sobre a resistência a compressão}

A granulometria do fino de carvão inferior a $0,045 \mathrm{~mm}$ foi outro objeto de estudo do presente trabalho. A Figura 7 apresenta os resultados obtidos no período analisado. Os ensaios mostraram que na faixa granulométrica analisada, ou seja, entre 70 a $90 \%$ a resistência à compressão aumentou de maneira bem sutil à medida que 0 percentual do material (carvão moído) passante na malha de $0,045 \mathrm{~mm}$ elevou-se. Em comparação com as outras variáveis analisadas, a granulometria foi a que menos influenciou nos resultados de compressão. Essa analise esta em conformidade com a literatura consultada [9].

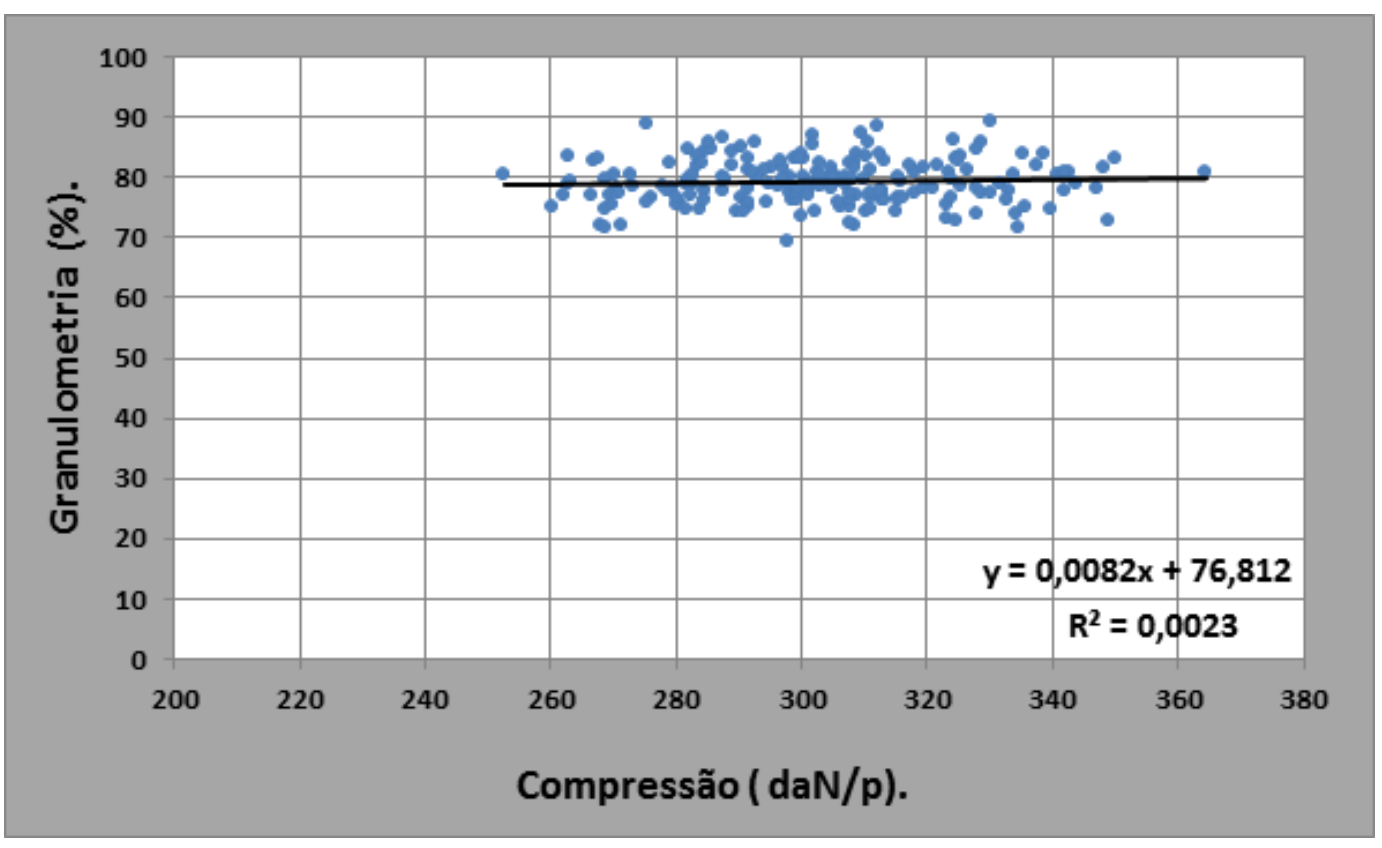

Figura 6 - Influência da porosidade sobre a resistência a compressão. 


\section{CONCLUSÃO}

A utilização de antracito na pelotização de minério de ferro contribui positivamente para a redução de custos com combustíveis, além de promover uma queima mais eficiente das pelotas. No entanto, para valores de carbono fixo em massa superior a $1,05 \%$ houve uma redução nos resultados de compressão.

As pelotas destinadas para alto-forno, devido a maior quantidade de $\mathrm{CaO}$ utilizado, apresentaram melhores resultados de compressão diante de dosagens de carbono fixo superior a $1,2 \%$.

Em comparação direta com a literatura analisada [3], os resultados de resistência à compressão foram mais tímidos diante das variações de percentual em massa de carbono fixo adicionado. Esse comportamento esta relacionado com a menor variação da massa de carvão utilizado nos processos industriais.

Há uma correlação da porosidade interna da pelota com a resistência à compressão, de modo que, pelotas com percentuais de porosidade maiores apresentam menores valores de resistência à compressão devido à redução da área interna.

$\mathrm{Na}$ faixa granulométrica entre 70 e 90\% de carvão moído passante na malha da peneira de $0,045 \mathrm{~mm}$, praticamente não houve alteração nos resultados de resistência à compressão. Dentre as variáveis estudadas, esta foi a que menos impactou na resistência das pelotas. 


\section{REFERÊNCIAS}

1 CCGE (Centro de Gestão e Estudos Estratégicos). Siderurgia no Brasil 20102025. Série de Documentos Técnicos. 2010; n9:21-116p.

2 RIGAUD M, PANIGRAPHY SC, JENA B. Characterization of fluxed pellets produced from low silica specular hematite. CIM BULLETIN.1992; 85(964):09$102 p$.

3 MEYER, K. Pelletizing of Iron Ores. Springer - Verlag Berlin, Heidelberg, and Verlag Stahleissen mbH. Düsseldorf, Germany. 1980; 21-205.

4 COSTA, RV. Otimização da resistência à compressão de pelotas de minério de ferro para redução direta pela aplicação de projeto robusto [tese de mestrado].Ouro Preto: Universidade Federal de Ouro Preto; 2008.

5 FONSECA, MC. Influência da distribuição granulométrica do pellet feed no processo de aglomeração e na qualidade da pelota de minério de ferro para redução direta[tese de mestrado].Ouro Preto: Universidade Federal de Ouro Preto; 2004.

6 BOECHAT, FO, PEREIRA, PM, SIMOES, HO, PASSIGATTI, VP, MAGNAGO, D, BAILON, AMG, MOREIRA, JL. Influência da distribuição granulométrica do calcário e antracito na qualidade física e metalúrgica das pelotas de minério de ferro. In:Associação Brasileira de Metalurgia, Materiais e Mineração. Anais do $41^{\circ}$ Seminário de Redução Direta de Minério de Ferro e Matérias-Primas e $12^{\circ}$ Seminário Brasileiro de Minério de Ferro; 2011; Vila Velha; Brasil; p.173-182.

7 SÁ KG. Estudo da influência da mineralogia dos tipos de minério da Samarco Mineração sobre a resistência a compressão de pelotas para processos de redução direta[tese de mestrado]. Ouro Preto: Universidade Federal de Ouro Preto; 2003.

8 YANG YH. Fundamental study of pore formation in iron ore sinter and pellets [tese de doutorado]. Wollongong: University of Wollongong.1990; 36-217.

9 PEREIRA, Priscilla M. Influência do Antracito Adicionado à Mistura de Pelotização Sobre as Características Físicas das Pelotas Queimadas[tese de mestrado]. Belo Horizonte: Universidade Federal de Minas Gerais; 2016. 